\title{
ON THE QUESTION OF THE SPECIFICITY OF CORRECTION OF FOREIGN STUDENTS SPEECH MISTAKES IN THE CONDITIONS OF COMMUNICATIVE-ORIENTED EDUCATION IN RUSSIAN (UKRAINIAN)
}

\author{
Maryna Komina \\ Candidate of Philological Sciences, Associate Professor \\ Kharkiv National University \\ of Civil Engineering and Architecture \\ (Kharkiv, Ukraine) \\ e-mail: komina.maryna@kstuca.kharkov.ua
}

\begin{abstract}
The aim of the article was to find out the expediency and specifics of correcting mistakes in the oral speech of foreign students within the communicative-oriented approach to learning a foreign language. The theoretical and methodological basis of the work consists of the materials of Russian and Ukrainian scientists, devoted to the coverage of theoretical aspects of the concept of linguistic mistakes, the main types and methods of its correction. Research methods such as comparative, analytical and linguocultural was used. Depending on the division criteria, the main types of linguistic mistakes were identified, including intralingual and interlingual; phonetic, lexical-semantic, morphological-syntactic and pragmatic; mistakes of performance and competence, etc. It was proposed to consider the correction of speech mistakes as a kind of linguodidactic strategy that combines a set of processes of identification, correlation, selection and prevention of the most common linguistic mistakes, in particular when teaching Russian (Ukrainian) as a foreign.
\end{abstract}

Keywords: linguistic mistakes, oral speech, communicative-oriented approach, self-correction, mutual correction, nationally oriented learning.

\section{К ВОПРОСУ О СПЕЦИФИКЕ ИСПРАВЛЕНИЯ РЕЧЕВЫХ ОШИБОК ИНОСТРАННЫХ СТУДЕНТОВ В УСЛОВИЯХ КОМУНИКАТИВНО-ОРИЕНТИРОВАННОГО ОБУЧЕНИЯ РУССКОМУ (УКРАИНСКОМУ) ЯЗЫКУ}

\author{
Марина Комина \\ Кандидат филологических наук, доцент \\ Харьковский национальный университет \\ строительства и архитектуры \\ (Харьков, Украина) \\ e-mail: komina.maryna@kstuca.kharkov.ua
}

\begin{abstract}
Аннотация. Целью статьи было выяснить целесообразность и специфику исправления ошибок в устной речи студентов-инофонов в рамках коммуникативно-ориентированного подхода к обучению иностранному языку. Теоретико-методологическую базу работы составляют материалы российских и
\end{abstract}


украинских ученых, посвященные изложению теоретических аспектов понятия лингвистической ошибки, основных типов и методов ее коррекции. Использованы такие методы исследования: сравнительно-сопоставительный, аналитический и лингвокультурологический. В зависимости от критериев различения выделены основные типы лингвистических ошибок, среди которых интралингвистические и межъязыковые; фонетические, лексико-семантические, морфологосинтаксические и прагматические; ошибки перфоманции и компетенции и т. д. Предложено рассматривать коррекцию речевых ошибок как своеобразную лингводидактическую стратегию, совмещающую в себе совокупность процессов идентификации, соотношения, отбора и предупреждения самых распространенных лингвистических нарушений, в частности во время преподавания русского (украинского) как иностранного.

Ключевые слова: лингвистическая ошибка, устная речь, коммуникативно-ориентированный подход, самокоррекция, взаимокоррекция, национально ориентированное обучение.

\section{ВВЕДЕНИЕ}

Проблема исправления ошибок в устной речи студентов занимает одно из центральных мест в методике преподавания иностранного языка, в частности украинского или русского. Ее решение является залогом обеспечения процесса коммуникации как едва ли не важнейшей задачи изучения языка. Однако стоит обратить внимание на специфику контроля за устной речью студента, в частности на то, что, согласно концепции коммуникативно-ориентированного обучения, основной задачей этого вида деятельности является формирование коммуникативной компетенции инофона, а это значит: ведущее значение приобретает именно содержание студенческого высказывания, тогда как исправление ошибок в таком случае является вторичным. Тем не менее преуменьшать роль коррекции устных ошибок, тоже не стоит, поскольку именно они «сигнализируют о проблемах усвоения, объективных трудностях овладения языковым материалом, недостаточном уровне автоматизации речевых клише» (Uchebnik russkogo yazyka dlya polyakov 1963; Los' 2013).

\section{ОБЗОР ЛИТЕРАТУРЫ. МЕТОДЫ ИССЛЕДОВАНИЯ}

Обозначенная тема является широко изученной в научном мире, о чем свидетельствует значительное количество отечественных и зарубежных исследований, в основном посвященных феномену ошибки, причинам ее возникновения, предупреждения и исправления (Е. Верещагин, М. Всеволодова, Г. Китайгородская, Е. Пасов, В. Цетлин и др.). В области же лингводидактики, в частности с точки зрения формирования иноязычной компетенции, проблему изучали П. Тишулин, Н. Кондрашова, А. Лось, В. Вараксина, М. Архарова и др. Однако общепринятой стратегии исправления и предупреждения ошибок в устной речи иностранных слушателей курса «Русский (украинский) язык как иностранный» до сих пор не существует. Поэтому цель нашей работы проанализировать наиболее распространенные типы ошибок в устной иноязычной речи студентов; выяснить основные причины их возникновения и обобщить наиболее действенные методы и приемы их исправления или предупреждения.

Для решения поставленных задач применены следующие методы: сравнительносопоставительный анализ, с помощью которого возможно выявление общих и отличительных свойств в структуре родного (или английского как интернационального) студентам языка и языка обучения; аналитический и лингвокультурологический.

Относительно теоретических аспектов указанного вопроса установлено, что языковая ошибка - это некорректный для определенных условий функционирования выбор единиц из ряда одноуровневых или среди членов одной парадигмы. По словам Н. Кондрашовой, такие ошибки 
связаны с дидактическими причинами или с явлением языковой интерференции (Kondrashova 2015). Роль лингвистических и психологических причин акцентировала В. Вараксина: речевая ошибка рассматривалась как специфический тип экспликации средствами иностранного языка своей картины мира, калькирование которой приводит к нарушению законов построения и правил функционирования изучаемой языковой системы (Varaksina 2014). Таким образом, рассмотрение явлений русского (украинского) языка сквозь призму иноязычной идентификации позволит педагогу выявить принципы организации и преподавания речевого материала в иноязычной аудитории, а также определить пути формирования вторичной языковой компетенции.

Под исправлением же следует понимать любую реакцию несогласия с содержанием или формой выражения. Подобные действия, как известно, могут проводиться преподавателем, собственно студентом или другими студентами (Tishulin 2012). Таким образом, в условиях новейших тенденций развития образовательного процесса, когда студент является не объектом, а субъектом обучения, преподаватель может перевести эту не слишком приятную в психологическом плане функцию на других участников речевой ситуации, тем самым подчеркнув активную позицию самого говорящего и важность самокоррекции или коррекции со стороны других вещателей (взаимокоррекции) (Kondrashova 2015). Выбор корректировщика, то есть лица, исправляющего ошибки, представляется не менее ответственной задачей, требующей решения педагогом при выборе единой стратегии корректировки ошибок в устной речи.

Еще одним важным аспектом является идентификация ошибки перед ее исправлением, поскольку традиционное «исправление ради исправления», когда преподаватель, подчеркивая ошибку, требует от студента знания теоретических правил, просто не имеет смысла. Поэтому в коммуникативной методике решение «исправлять» или «не исправлять» ошибки должно приниматься в соответствии с видом и целью работы (Los' 2013).

Далее постараемся классифицировать основные типы лингвистических нарушений, учитывая различные критерии. Так по типу интерференции ошибки делятся на две большие группы: интерлингвальные, или межъязыковые (зависят от речевого взаимодействия), причиной возникновения которых является межъязыковая интерференция, и интралингвальные, или внутриязыковые, возникающие вследствие внутриязыковых интерференций, то есть перепутывания категорий изучаемого языка (Kondrashova 2015).

В зависимости от языкового уровня различают следующие ошибки: фонетические (фонологические), лексико-семантические (употребление слов, которые не соответствуют общему контексту, или искривление значения лексем), морфолого-синтаксические (например, ошибка в окончании во время склонения глагола или нарушение порядка слов) и прагматические (высказывание некорректное для конкретной ситуации) (Tishulin 2012).

К типологии социокультурных отклонений ученая Н. Кондрашова причисляет: ошибки на уровне социокультурных знаний, то есть ложное осмысление вспомогательной контекстуальной лексики; ошибки на уровне речевого поведения коммуникантов (например, выбор интонации, расстановка пауз, темп речи, характерные для родного языка студента); ошибки на фоне общей письменной культуры речи (например, неправильное употребление форм обращения); поведенческие или экстралингвистические, невербальные (непосредственно не связанные с использованием иностранного языка, но такие, которые прямо влияют на качество процесса общения, например, нарушение норм коммуникативного поведения: коммуникабельность - молчаливость, эмоциональность - сдержанность; несоблюдение правил выбора формы одежды). Для предупреждения такого типа ошибок, связанных с недостаточным уровнем социокультурной компетентности, необходимо своевременно акцентировать межкультурные различия (Kondrashova 2015, 36-36).

Общепризнанным является также различение ошибок перфоманции и компетенции. Например П. Тишулин под первыми подразумевает несистемные отклонения, их может 
идентифицировать сам студент, чего нельзя сказать об ошибках компетенции, поскольку тот, кто изучает язык, или еще совсем не знаком с его структурой и поэтому ошибается, или просто неправильно понимает какое-то явление или категорию (Tishulin 2012).

Если говорить о результативной коррекции ошибок в устной иноязычной речи, прежде всего следует отметить, что она в основном зависит от методов обучения и выбранной учебной концепции. В частности, по мнению Н. Кондрашовой, методы, направленные преимущественно на изучение структурных особенностей языка (грамматико-переводной и т. д.), требуют исправления всех ошибок без исключения, в то же время как, например, коммуникативный, предусматривает вмешательство преподавателя в речь студентов только в крайнем случае: целью обучения признается умение участвовать в коммуникации, а языковой грамотности отводится второстепенная роль. Речевые нарушения в зависимости от влияния на понимание языка, по словам Н. Кондрашовой, опирающейся на позицию Г. Китайгородской, разделяют на коммуникативно значимые («сильные ошибки»), препятствующие пониманию смысла высказывания, и коммуникативно незначимые («слабые» ошибки), которые чаще всего являются отклонением от определенных языковых норм, но не влияют на понимание смысла сообщения в целом (Kitaygorodskaya 2009; Kondrashova 2015).

\section{ОСНОВНАЯ ЧАСТЬ}

Далее считаем целесообразным привести несколько примеров типичных речевых ошибок на начальном уровне овладения языком. К таким, конечно, относятся нарушения на всех уровнях, что объясняется ограниченностью словарного запаса и еще недостаточно сформированными коммуникативными навыками, но мы сосредоточимся именно на грамматических ошибках.

Так, например, безличные предложения составляют большую сложность для инофонов, прежде всего потому, что подобные конструкции преимущественно отсутствуют в грамматической системе большинства языков:

\section{Я надо}

Мне надо идти в университет.

Сегодня дождиво.

По нашему мнению, лучшей тактикой для исправления ошибки может стать различение конструкций со значением действия и описывающих состояние. Например, в первом предложении стоит обратить внимание на субъект, который выполняет действие. В противном случае, подчеркнем отсутствие активного деятеля и потребности в нем. Подобную модель исправления ошибки можно отрабатывать в смешанных иностранных группах, используя упражнения с синонимичными рядами и по возможности учитывая особенности грамматической структуры родного языка каждого инофона.

\section{Я меня есть}

Употребляя в данном контексте местоимение первого лица единственного числа, говорящий продуцирует простое предложение с двумя субъектами, что, как известно, противоречит основой идее грамматики. По словам А. Павлова, в этой ситуации стоит разделить понятия «обладания чемлибо и ощущение чего-либо, что характеризует употребление Дательного падежа с наречием или категорией состояния на -о» (Pavlov 2018). Таким образом, независимо от состава группы преподаватель в данном случае может задействовать традиционный способ устранения этой ошибки - аппеляцию к структуре предложения с одним субъектом + значение пассивного обладания чемлибо (Pavlov, 2018).

\section{Двойное отрицание}

Я всегда не работаю по праздникам.

У нее нет детей.

Основные сложности в данной ситуации связаны преимущественно с моментами отсутствия диференциации между не и нет; ошибочным по аналогии с интернациональным английским языком 
наличием в предложении с двумя семантическими категориями отрицания только одного отрицательного компонента; не различение слов «нет» и «нету». Соглашаясь с мыслью ученого А. Павлова, резюмируем, что первый случай относится к комуникативно значимым ошибкам, которые значительно искажают смысл речевого сообщения, быстро укореняются в сознании учащегося и представляют существенную сложность для исправления. Поэтому необходимо своевременно провести работу по ее устранению. Предлагается, подробно рассмотреть информацию о предикации в предложении: «наличие глагола предполагает употребление отрицательной частицы не, а отрицательная конструкция отсутствия чего-либо включает в свой состав нет и Родительный падеж существительного» (Pavlov 2018). Методологически правильно подобранные упражнения на усвоение этого формального принципа помогут закрепить полученные знания и предупредить подобные ошибки в дальнейшем. Во втором представленном предложении в качестве стратегии искоренения ошибки необходимо обратить внимание студента на то, что в случае с негативной формой глагола местоимение, которое употребляется в предложении, также отрицательное (Pavlov 2018).

Также считаем необходимым выделить основные способы корректировки ошибок в устной речи, которые, по нашему мнению, являются наиболее целесообразными в условиях коммуникативно ориентированного подхода к преподаванию иностранного языка в целом и русского (украинского) в частности.

\section{Невербальные средства.}

Для обеспечения непрерывности процесса общения преподаватель заранее предупреждает студентов о значении того или иного жеста или выражения лица. Озабоченного или удивленного вида учителя часто бывает достаточно, чтобы указать на проблему. Жесты также могут указывать на различные типы ошибок. Например, чтобы подчеркнуть необходимость прошедшего времени, показать назад через плечо. Поднятый вверх палец может означать место, где именно была допущена ошибка. Мы можем исправлять молча, тем самым подталкивая студента к самокоррекции. Показывая аудитории ладонь, демонстрируем пальцы один за другим, будто это слова в произнесенном предложении. Эта стратегия работает особенно хорошо, если ученик пропустил слово в предложении, поскольку он видит, в каком именно месте высказывания должно быть слово. В целом же отбор жестов для исправления ошибок зависит от конкретной учебной ситуации.

Фонетические символы. Если аудитория знакома с фонетическими символами чужого для них языка, стоит их применять для привлечения внимания к неправильно произнесенным звукам, указывая на соответствующие символы в фонематической таблице или изображая соответствующий символ на доске.

Эхо-коррекция. Она означает повторение неправильно сказанного учеником с вопросительной интонацией. Конечно, названный метод не может быть применен на начальном этапе обучения, в основном он является эффективным тогда, когда ученики допускают незначительные оговорки, которые вполне могут исправить сами.

Идентификация ошибки. В некоторых случаях просто необходимо вовремя указать аудитории на ошибку, сосредотачивая внимание на ней, поскольку она является коммуникативно значимой и влияет на смысл сообщения. Описанная тактика чаще применяется к ошибкам, которые обусловлены недостаточным уровнем владения материала. Мы можем сказать: «Вы уверены?», чтобы указать на ошибку, а потом озвучить правильный вариант.

Отложенное исправления. Во время тех видов деятельности, которые требуют непосредственно свободной речи (ролевые игры), исправление ошибок вообще не целесообразно. Соответственно этот процесс откладывается до специально выбранного для этого момента. После окончания задачи можем озвучить аудитории допущенные погрешности или представить неправильные варианты наглядно, чтобы стимулировать самокоррекцию, попросить предложить 
правильные варианты, при этом не идентифицируя каждую конкретную ошибку с тем, кто ее допустил.

Игнорирование ошибок. По нашему мнению, вполне правомерным является игнорирование ошибок, которые принадлежат к высшему уровню компетентности, чем тот, которым обладают учащиеся в конкретный период учебного процесса. Допустимым вариантом считаем переформулировать часть высказывания, но не ожидаем, что студент сможет исправиться. Также не следует заострять внимание на нарушениях в устной речи конкретного ученика, процесс обучения которого существенно зависит от его психо-эмоционального состояния (новичок в компании, слишком чувствительная личность меланхолического типа темперамента и под.). Индивидуальный подход к решению подобных проблемных ситуаций является оптимальным. Также для сохранения общей благоприятной коммуникативной атмосферы в группе иностранных студентов не следует замечать оговорки, которые можно отнести к техническим ошибкам и исправить самостоятельно.

Переформулировка. Это тактика, которую используют родители, когда их маленькие дети говорят неправильно. Взрослые сразу же правильно повторяют высказывание, не привлекая внимание ребенка к ошибке, а те в свою очередь машинально озвучивают сказанное, запоминая правильную модель коммуникации. Сродни осторожному, но целенаправленному родительскому голосу, голос преподавателя иностранного языка может стать мощным инструментом практически подсознательного улучшения устной речи студента.

Объяснение правила, приведения примера или определения. Этот метод следует применять при работе с группой продвинутого уровня владения иностранным языком и студентами старшего возраста, поскольку у них совершенно другая мотивация, связанная со значительной занятостью и желанием максимального результата за короткий срок.

По словам А. Лось, среди самых распространенных методов исправления речевых ошибок иностранных студентов стоит отметить метод коррекции путем анализа ошибки; фокусировки лишь на наиболее распространенных погрешностях путем использования наглядности с изображением неправильного варианта; «подслушивания» за работой студентов в микрогруппах; метод привлечения жестов. Продуктивна в этом плане также работа в студенческих группах, объединенных по общности грамматических проблем. Принципиальное отличие такого упражнения заключается в возможности исправления проблемного момента самими студентами в условиях коллективной работы. Бесспорно, такое взаимодействие создает в группе благоприятную атмосферу, нейтрализует напряжение, которое часто возникает, когда ошибку отмечает преподаватель (Los' 2013). Вероятно, самым действенным, по нашему мнению, является исправление нарушений в контексте такого альтернативного метода как суггестопедия. Речь идет о создании специфической атмосферы, что должно стимулировать процесс обучения. К тому же студент на первом занятии получает так называемую новую, иностранную, идентичность (иностранное имя, место жительства в стране, язык которой изучает, новую профессию и т.д.). Во время занятий он просто играет роль, а педагог учитывает это, даже когда исправляет ошибки, соответственно, можно предположить, что все свои ошибки и негативную реакцию преподавателя на них студент соотносит с новой ролью, поэтому воспринимает спокойнее (Tishulin 2012).

Мы убеждены, что именно ошибки студентов, в частности, речевые погрешности, дают возможность преподавателю продумать и создать наиболее оптимальную для конкретной группы студентов систему преподавания и коррекции речи иностранцев. Проанализировав нарушения в речи студентов в качестве «отрицательного языкового материала» (Shcherba 2004), можно сделать выводы о граматической системе его родного языка (падежный / беспадежный, об особенностях фунционирования глагольных форм), в дальнейшем учитывая и сопоставляя их при подаче нового материала. В связи с этим на современном этапе все большую популярность преобретает национально ориентировный подход к обучению иностранным языкам в условиях иноязычной среды. Соглашаясь с мнением К. Дэпонян, подчеркнем, что такой взгляд является комплексным: «с одной 
стороны, в его основе лежат идеи коммуникативного и социокультурного подходов, а с другой - он требует учета ряда лингводидактических факторов, которые в условиях иноязычной среды оказывают большое влияние на обучение языку» (Deponyan 2015).

\section{РЕЗУЛЬТАТЫ ДИСКУССИИ}

Подытоживая, отметим, что исправление ошибок в устной иноязычной речи на занятиях по русского (украинского) языку как иностранному можно квалифицировать как своеобразную лингводидактическую стратегию, которая предусматривает идентификацию ошибки, соотношение ее с уровнем языковой подготовки конкретного студента, фазой занятия и выбор наиболее целесообразного метода ее коррекции. Среди факторов, которые следует учитывать при реализации этой стратегии назовем следующие: ошибка - нормальное явление процесса обучения; исправлять надо ошибки, а не учащегося; нельзя корректировать в момент творческого акта речевого общения; исправление ошибки должно всегда носить характер предъявления и повторения правильной формы за преподавателем. При этом объяснение, если оно необходимо, носит характер напоминания, а не разъяснения грамматических сведений и правил. Иногда гораздо целесообразнее одновременно с озвучиванием правильной формы добавить несколько примеров данной системы явлений. По сути дела они и будут объяснением погрешности. Такой подход к ошибкам позволяет преподавателю добиться свободы в общении, так как избавляет учащихся от напряжения, связанного прежде всего с боязнью допустить ошибку.

\section{ЗАКЛЮЧЕНИЕ}

Перспективной считаем разработку новейших методов исправления речевых ошибок, центральное место в которых будет занимать удачно организованная педагогом студенческая самокоррекция.

\section{LIST OF REFERENCES}

Varaksina, V. A. (2014). Rechevue oshibki inostrannuh studentov i prichiny ih vozniknoveniya [Speech mistakes of foreign students and the reasons for their occurrence] / V. A. Varaksina // Yazyk i text langpsy.ru. No. 1. - Rejym dostupa: http:// langpsy.ru/journal/2014/1/Nurmuhhmetov.phtml

Deponyan, K. A. (2015). Russkiy yazyk kak inostrannyy v usloviyakh Yuzhnoy Korei: rol' rodnogo yazyka uchashchikhsya $\mathrm{v}$ otbore uchebnogo materiala [Russian language as a foreign language in the conditions of South Korea: the role of the native language of students in the selection of educational material] / K. A. Deponyan // Gumanitarnyye, sotsial'no-ekonomicheskiye i obshchestvennyye nauki. No. 3 Chast' 1, 2. - S. 212-216. - Rejym dostupa: https://rucont.ru/efd/427456

Kitaygorodskaya, G. A. (2009). Intensivnoye obucheniye inostrannym yazykam. Teoriya i praktika [Intensive teaching of foreign languages. Theory and practice] / G. A. Kitaygorodskaya. - M.: Vysshaya shkola; Nots «Shkola Kitaygorodskoy»; Izdaniye 2-ye, pererab. i dop., 277 s.

Kondrashova, N. V. (2015). Prognozirovanie i ispravlenie studencheskih oshibok pri obuchenii inostrannym yazikam [Prediction and correction of student mistakes in teaching foreign languages] / N. V. Kondrashova // Nauchniy dialog. No. 7 (43). - S. 27-47.

Los', O. V. (2013). Pro deyaki aspekty poperedjennya ta vypravlennya pomylok v inshomovnomu movlenni [About some aspects of prevention and correction of mistakes in foreign speech] / O. V. Los' // Pedagogichni nauky: theoriya, istoriya, innovatciyni technologii. № 8. - S. 133-142. 
Pavlov, A. I. (2018). Tipichnyye yazykovyye oshibki inostrantsev (B1-B2) [Typical language mistakes of foreigners (B1-B2)] / A. I. Pavlov // Filologicheskiy aspekt. Vyp. 6. - Rejym dostupa: // http://scipress.ru/philology

Tishulin, P. B. (2012). Vidy yazykovyh oshibok i vozmojnozti ih ispravleniya pri obuchenii inostrannomu yazyku [Types of language mistakes and the possibility of their correction in teaching a foreign language] / P. B. Tishulin // Izvestiya vyshih uchebnyh zavedeniy. Povoljskiy region. Humanitarnye nauki. No. 1 (21). - S. 132-137.

(1963). Uchebnik russkogo yazyka dlya polyakov: (1 god obucheniya) [Textbook of the Russian language for Poles: (1 year of study)] / M. V. Vsevolodova, L. P. Yudina. - M.: Izd-vo Mosk. un-ta, 400 s.

Shcherba, L. V. (2004). Yazykovaya sistema i rechevaya deyatel'nost' [Language system and speech activity] / L. V. Shcherba. - Yeditorial URSS, $432 \mathrm{~s}$.

\section{For citation:}

Komina, M. (2021) ON THE QUESTION OF THE SPECIFICITY OF CORRECTION OF FOREIGN STUDENTS SPEECH MISTAKES IN THE CONDITIONS OF COMMUNICATIVE-ORIENTED EDUCATION IN RUSSIAN (UKRAINIAN) // International Scientific-Pedagogical Organization of Philologists “ WEST-EAST " (ISPOP). Scientific Journal WEST-EAST. Vol 6 N1 (October, 2021). pp. 72-79. https://doi.org/ 10.33739/2587-5434-2021-6-1$72-79$

\section{Для цитирования:}

Комина, М. (2021) К ВОПРОСУ О СПЕЦИФИКЕ ИСПРАВЛЕНИЯ РЕЧЕВЫХ ОШИБОК ИНОСТРАННЫХ СТУДЕНТОВ В УСЛОВИЯХ КОМУНИКАТИВНО-ОРИЕНТИРОВАННОГО ОБУЧЕНИЯ РУССКОМУ (УКРАИНСКОМУ) ЯЗЫКУ // International Scientific-Pedagogical Organization of Philologists "WEST-EAST " (ISPOP). Scientific Journal WEST-EAST. Vol 6 N1 (October, 2021). C. 72-79. https://doi.org/ 10.33739/2587-54342021-6-1-72-79

Information about the author:

Komina Maryna - Candidate of Philological Sciences, Associate Professor Kharkiv National University of Civil Engineering and Architecture. Kharkiv, Ukraine.

e-mail: komina.maryna@kstuca.kharkov.ua

\section{Информация об авторе:}

Комина Марина - кандидат филологических наук, доцент кафедры украинского языка и языковой подготовки иностранных граждан Харьковского национального университета строительства и архитектуры. Харьков, Украина

e-mail: komina.maryna@kstuca.kharkov.ua

Manuscript received: 08/14/2021

Accepted for publication: 09/14/2021

Рукопись получена: 08/14/2021

Принята к печати: 09/14/2021

International Scientific-Pedagogical Organization of Philologists "West-East" ISPOP SCIENTIFIC JOURNAL “ WEST-EAST"

ISSN (print) - 2587-5434 ISSN (online) - 2587-5523

Index in SIS ID:7515

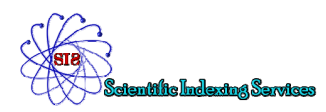

